\title{
Preparation and optical properties of PS @Au-Cu core-shell Nano composite
}

\author{
Rudainah $\mathrm{Ali}^{\mathrm{ab}}$, Farkad $\mathrm{Ali}^{\mathrm{c}}$, Lin $\mathrm{Yi}^{\mathrm{a}^{*}}$ \\ ${ }^{a}$ School of Physics, Huazhong University of Science and Technology, Wuhan 430074,PR China, \\ ${ }^{\mathrm{b}}$ Physics Department of College Science, Diyala University, Iraq, \\ ${ }^{\mathrm{c}}$ Ministry of Higher Education, Iraq \\ E-mail address: yilin@mail.hust.edu.cn
}

Keywords Copper - gold Nanoparticles; core -shell Nanoparticles; optical; plasmon absorption polystyrene.

\begin{abstract}
An appropriate low-cost uncomplicated chemical method has been used to obtain the optical properties in the production of plasmon by manufacturing nanomaterial's consisting of dielectric core and a shell that grows on its surface. This core consists of the polystyrene PS and a gold copper shell. The synthesis was made in two steps. In the first step PS core was fabricated, then coated by a shell consisting of $\mathrm{Au}-\mathrm{Cu}$ particles. The shell shape differs according to the change in the amount of molar concentrations of $\mathrm{Cu}$, and $\mathrm{H} 2 \mathrm{O} 2$. It is found that variation of this materials amount gives us absorbance measurements (Localised Surface Plasmon Resonance, LSPR) that increase proportionally with changing quantities directly, where the size of core is constant .And the peak position in blue shift high energy then changes to red shift low energy. This change depends on the size and shape of particles. The same case applies for the transmittance of its change with the change of this material. The nano shell was characterized by using Scanning electron microscopy,SEM and UV - vis spectroscopy by varying the amount of $\mathrm{Cu}$ and $\mathrm{H}_{2} \mathrm{O}_{2}$.
\end{abstract}

\section{1-INTRODUCTION}

There has been great attention in noble metal nanoshells, which are composite nanoparticles made of a dielectric core wrapped by a metal shell with a thickness of a few to a few tens nanometers .These nanostructured composite particles possess a helpful optical property of frequency-tunable localized surface plasmon resonance (LSPR) that originates from the resonant optical excitation of the collective oscillation of conduction electrons in the metal [1-4]. By varying the relative geometric dimensions of the dielectric core and the metal shell, the resonance of a nanoshell may be tuned over hundreds of nanometers in wavelength from the visible into the infrared region. Because of this unique frequency-tunable feature, metal nanoshells have found applications ranging from photonics and electronics to biomedical technology. In the concentric metal nanoshell structure,when the thickness of the interlayer spacing between the inner and outer nanoshell is small enough, the coupling strength and the energy between the plasmons on the inner and outer shell are strong, and the resulting plasmon energy differs dramatically from the isolated shell plasmons. It is also very interesting to reduce the interlay spacing to atomic level and replace the inner and outer shell of the concentric nanoshell with different kinds of metal, namely, alloy, and control the resulting surface plasmon by varying the alloying component. The tuning of SPR in intensity and wavelength is desired for the applications of SPR [5-7]

The layered nanoparticle with a dielectric core and a metallic nanoshell, known as a metal nanoshell, provides a tunable geometry in which the surface plasmon wavelength at the nanoshell surface can be precisely controlled by varying the core/shell ratio. For example, the surface plasmon resonance of a silica core-gold shell nanoshell can be varied over hundreds of nanometers in wavelength,across the visible and into the infrared region of the spectrum [6,7]. Recently, the studies of the plasmon energies of the concentric metal nanoshell structure supply us a new technique to manipulate the surface plasmon resonance [8]. 
There are many methods to fabricate core@shell nanostructure, for example, "seed and growth" [9], self-assembly [10], and ion sputtering [11] The most publicity way is perhaps the "seed and grow" method. By this approach, the surface of the dielectric core particle is functionalized, whereupon tiny gold seed nanoparticles are attached. This is then followed by reducing the metal format its ion solutions onto these 'seed' particles to form a complete metal shell around the dielectric core. In this paper, a facile method for preparing ps@Au-Cu nanoshell was presented. The emphasis of this experiment has been on producing nanomaterial's radiate plasmon . Changing the amount of molar concentrations of $\mathrm{Cu}$, and $\mathrm{H}_{2} \mathrm{O}_{2}$ played an extremely important role in changing the value of data absorption and the shape of figures .Nanoshells fabricated using the seed-and-growth method to get nanoshell structure give us good optical absorption (plasmon). Also the work shows the different absorption between ps@Au and ps@Au$\mathrm{Cu}$ nanoshell. Moreover, we described the preparation and characterization of ps@Au-Cu nanoshells by Scanning electron microscopy (SEM)and ultraviolet visible (UV-Vis) spectroscopy.

\section{EXPERIMENTAL METHOD}

We prepared PS@Au-Cu in the following way:

\subsection{PS seed}

Preparation PS seed, but $90 \mathrm{ml}$ water in beaker then add $13 \mathrm{ml}$ styrene. Unscrew $0.3 \mathrm{~g}$ from Polyvinylprrolidone $\left(\mathrm{C}_{6} \mathrm{H}_{9} \mathrm{NO}\right)_{\mathrm{n}}$ in $5 \mathrm{ml}$ water then add to the first .Solve $0.3 \mathrm{~g}$ Potassium Peroxy disuflat in $25 \mathrm{ml}$ water, add to them, then left the material in magnetic stir for 24 hours and temperature $70 \mathrm{C}^{\circ}$, after that washing 5 times using water .

\section{2 preparation of modified PS sphere}

Flask washing by using Ethanol, $50 \mathrm{ml}$ water, add $2 \mathrm{ml} \mathrm{PS}$ and $2 \mathrm{ml}$ PEI put with them in magnetic stir for one hour, then washing 6 times using water, $12000 \mathrm{r} / \mathrm{min}$ and $20 \mathrm{~min}$ the time for the one washing.

\subsection{Fabrication PS@Au seed}

$1 \mathrm{ml}$ from $\mathrm{HAuCl}_{4}$ add to $50 \mathrm{ml}$ water put on rigorous stir, solve $0.1381 \mathrm{~g}$ from $\mathrm{C}_{6} \mathrm{H}_{5} \mathrm{Na}_{3} \mathrm{O}_{7.5} \mathrm{H}_{2} \mathrm{O}$ in $12 \mathrm{ml}$ water take $2 \mathrm{ml}$ add to the mix and the $10 \mathrm{ml}$ remainder add to it $0.0078 \mathrm{~g}$ from $\mathrm{NaBH}_{4}$, take $1 \mathrm{ml}$ add to the solution after that put $3 \mathrm{ml}$ PS modified for $10 \mathrm{~min}$, left the solution on the side for 3 hours then washing 4 times using water.

\subsection{Preparation PS@Au-Cu}

Take $45 \mathrm{ml}$ water with $0.2 \mathrm{PS} @ \mathrm{Au}$ seed (Solve $\mathrm{CuSO}_{4} .5 \mathrm{H}_{2} \mathrm{O}$ in water ) add to them, after $5 \mathrm{~min}$ mix with them $1.5 \mathrm{ml} \mathrm{K}-\mathrm{H}$ and add $\mathrm{H}_{2} \mathrm{O}_{2}$, in different amount for half hour, then washing 3 times using water. We measured the absorption by UV and the morphology using the scanning electron Microscope ( SEM). 


\section{3-RESULTS AND DISCUSSIONS}

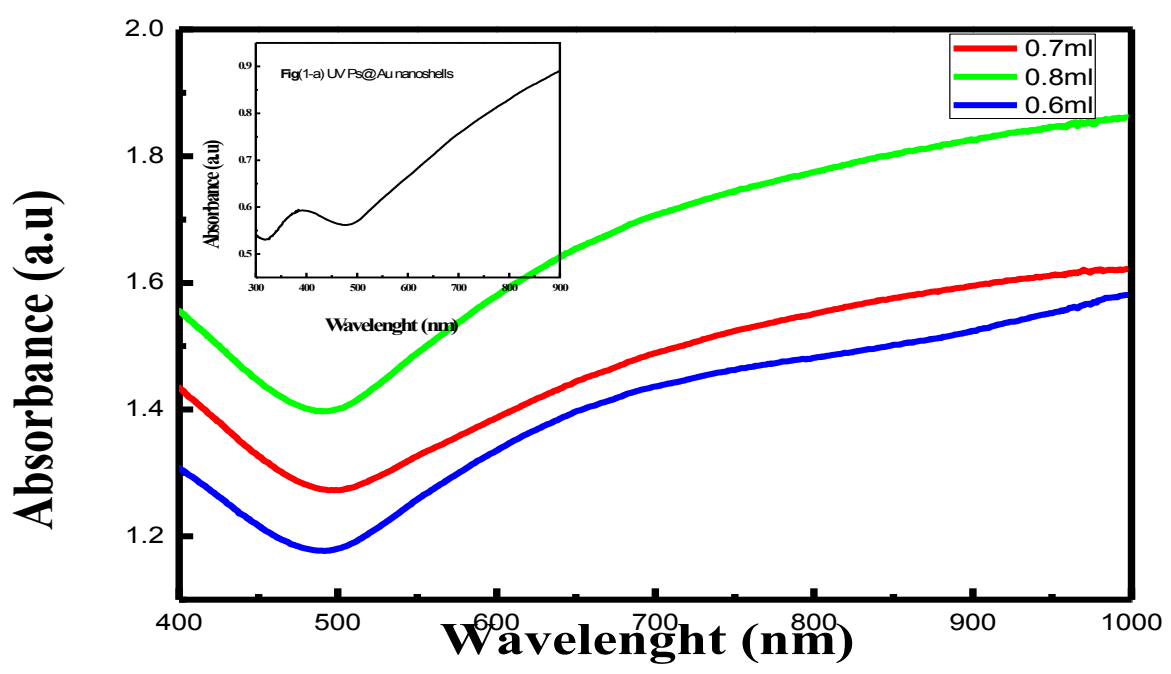

Figs (1-a) Ps@gold nanoshell, (1-b) UV-Vis absorption spectra of Ps@ gold- copper nanoshells which the volumes of $\mathrm{CuSO}_{4} .5 \mathrm{H}_{2} \mathrm{O}$ molar solution are (a) $6 \mathrm{ml}$; (b) $7 \mathrm{ml}$; (c) $8 \mathrm{ml}$; respectively.

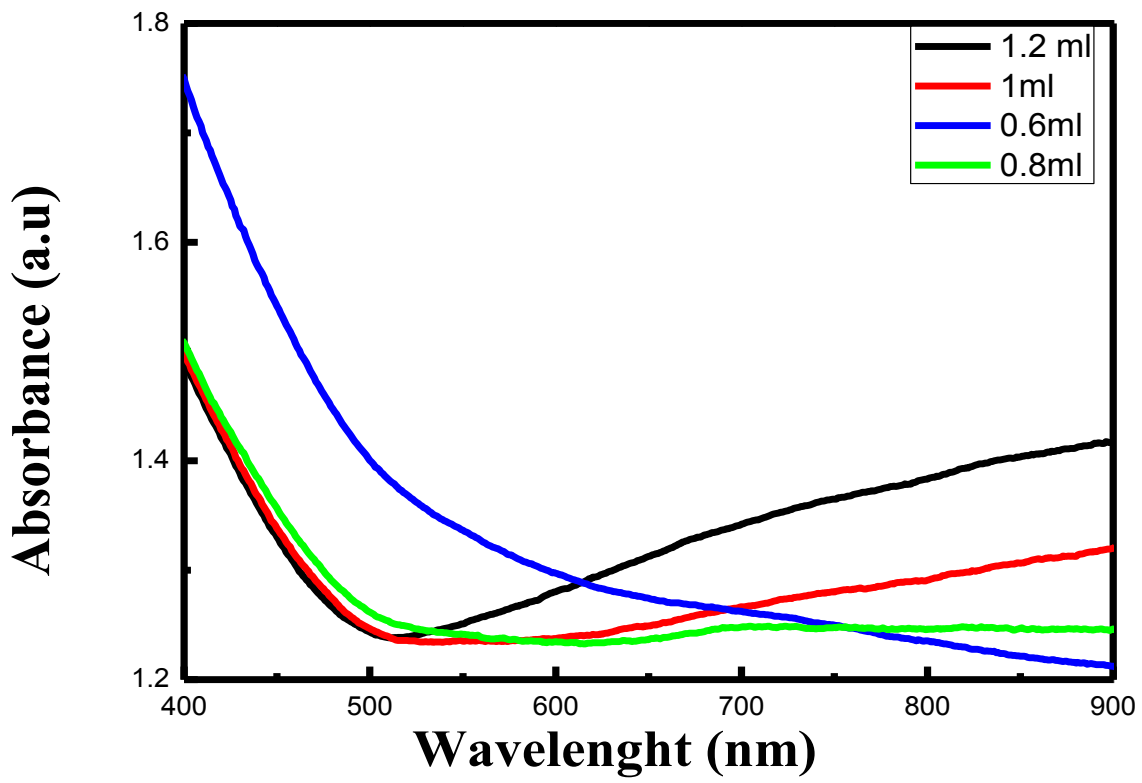

Fig (1-c) UV-Vis absorption spectra of Ps@ gold- copper nanoshells which the volumes of $\mathrm{H}_{2} \mathrm{O}_{2}$ solution are (a) $0.6 \mathrm{ml}$; (b) $0.8 \mathrm{ml}$; (c) $1 \mathrm{ml}$; (e) $1.2 \mathrm{ml}$ respectively.

Figs.1(a, b, c) show the optical absorption spectra for $\mathrm{Au}$ and $\mathrm{Cu}$ nanoparticles dispersed within the pores of monolithic mesoporous PS annealed at different amount of $\mathrm{CuSO}_{4} .5 \mathrm{H}_{2} \mathrm{O}, \mathrm{H}_{2} \mathrm{O}_{2}$. Fig. 1c includes the optical spectrum of PS@Au Nano shell which have peak about 400-500nm that return to the thick of Au shell around PS core that's appear in Fig.2 . For fig1b shows the UV-Vis absorption spectra of the PS/Au-Cu composites fabricated using different concentration of the $\mathrm{CuSO}_{4} .5 \mathrm{H}_{2} \mathrm{O}$ molar solution, where a clear plasmon is observed of Nano shells that's similar to[12] . The position and width of the SPR peak are linked with the size and shape of the metal particles, also connected with its own dielectric constant and that around it. With changing the anisotropy of particles, the peak would vary in the visible and near-infrared spectrum regions [13-14].However, as the gold-copper coverage increased from a low to a high level, the Au-Cu NPs density 
and the contacting area between Au-Cu NPs and PS supports would increase; so, the absorption spectra of PS/Au-Cu composites are mainly blue-shifted and then change to red shift that's depended on the molar solution of $\mathrm{CuSO}_{4} \cdot 5 \mathrm{H}_{2} \mathrm{O}$ and the size, shape of naoparticles. The results may be explained as follows. As the gold-cooper coverage increases to a high level, the PS/Au-Cu composites mainly show the collective absorption behavior of the $\mathrm{Au}-\mathrm{Cu} \mathrm{NPs}$. This finding is consistent with the SEM images shown in Figure 4A-C The same phenomena had been observed with other [15] [16]. About fig $1 \mathrm{~d}$ the variety amount of $\mathrm{H}_{2} \mathrm{O}_{2}$ leads to small change in absorption but also big value from $\mathrm{H}_{2} \mathrm{O}_{2}$ gives high value for absorption according to the shape in fig 4D-G.

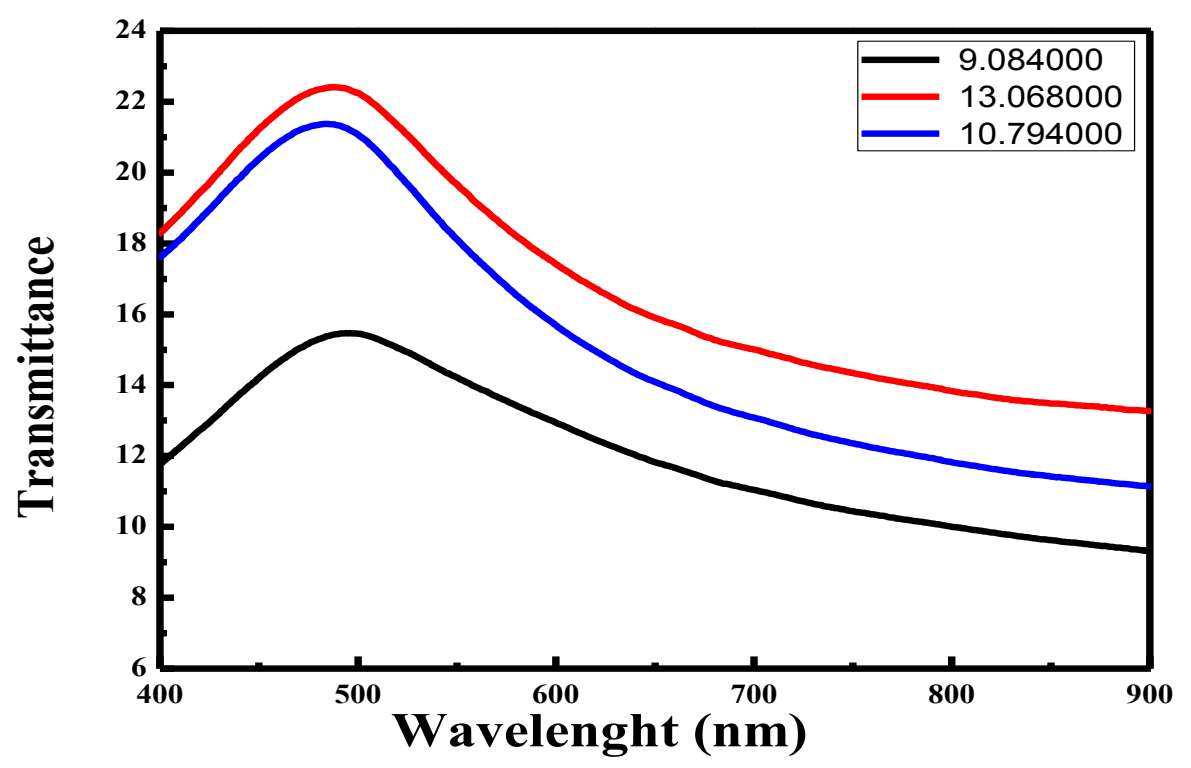

Fig (2-a) UV-Vis transmittance spectra of Ps@ gold- copper nanoshells which the volumes of $\mathrm{CuSO}_{4} \cdot 5 \mathrm{H}_{2} \mathrm{O}$ molar solution are (a) $6 \mathrm{ml}$; (b) $7 \mathrm{ml}$; (c) $8 \mathrm{ml}$; respectively

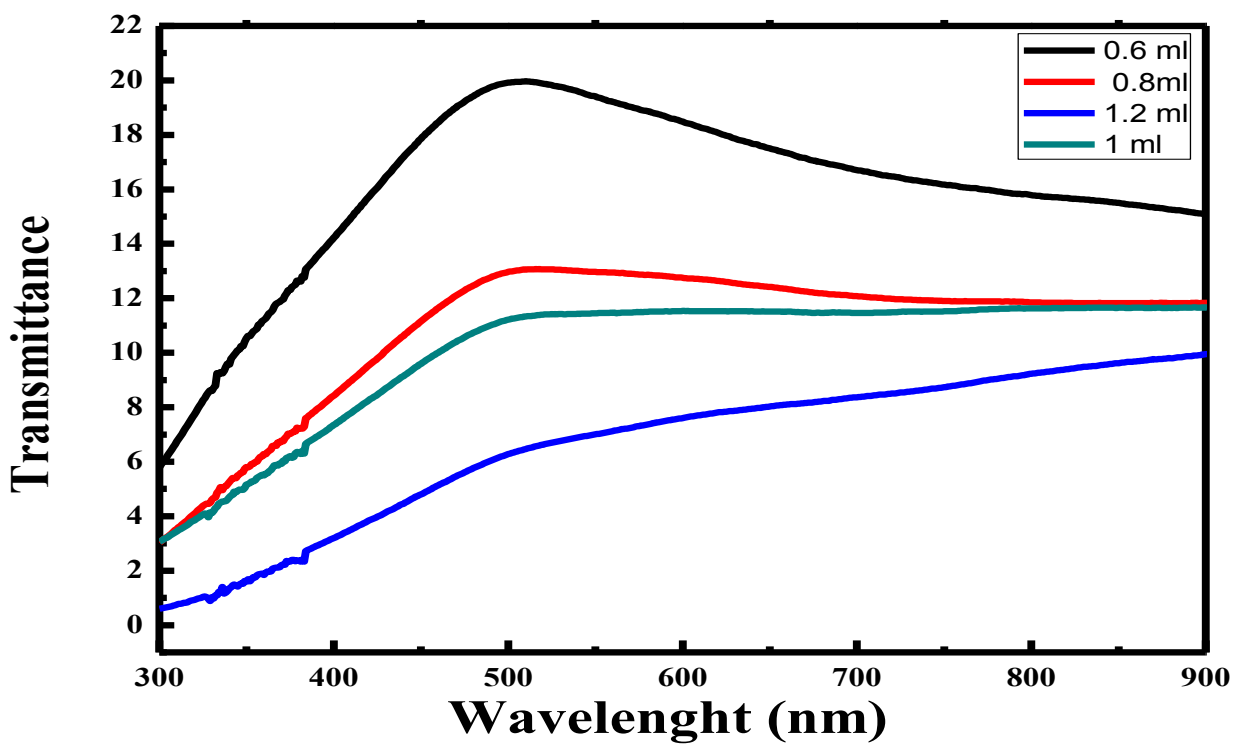

Fig (2-b) UV-Vis transmittance spectra of Ps@ gold- copper nanoshells which the volumes of $\mathrm{H}_{2} \mathrm{O}_{2}$ solution are (a) $0.6 \mathrm{ml}$; (b) $0.8 \mathrm{ml}$; (c) $1 \mathrm{ml}$; (e) $1.2 \mathrm{ml}$ respectively. 
The transmittance for composite PS@Au-Cu core shell studied in figure 2a-2-b , we can see different values for transmittance its vary with the changing values, where the changes in the quantities led_to diversity shape (can see figs 5A-5G), that's make effect on the optical properties, where more particles $\mathrm{Au}-\mathrm{Cu}$ growth on the surface core PS this particles soak up large quantity of light . Absorbance is the amount of light absorbed by a sample . It is calculated from $\mathrm{T}$ or $\% \mathrm{~T}$ using the following equations:

$$
\begin{gathered}
A=-\log _{10} \mathrm{~T} \text { or } \mathrm{A}=\log _{10}(1 / \mathrm{T}) \\
\mathrm{A}=2-\log _{10} \% \mathrm{~T}
\end{gathered}
$$

From absorbance, one can calculate the quantity known as transmittance (T). These equations reveal that transmittance and absorbance are inversely related. That is, the more a particular wavelength of light is absorbed by a substance, the less it is transmitted. Moreover, the inverse relationship between $\mathrm{A}$ and $\mathrm{T}$ is not linear, it is logarithmic that is evident from the above formats

\section{SEM Images Deformed}

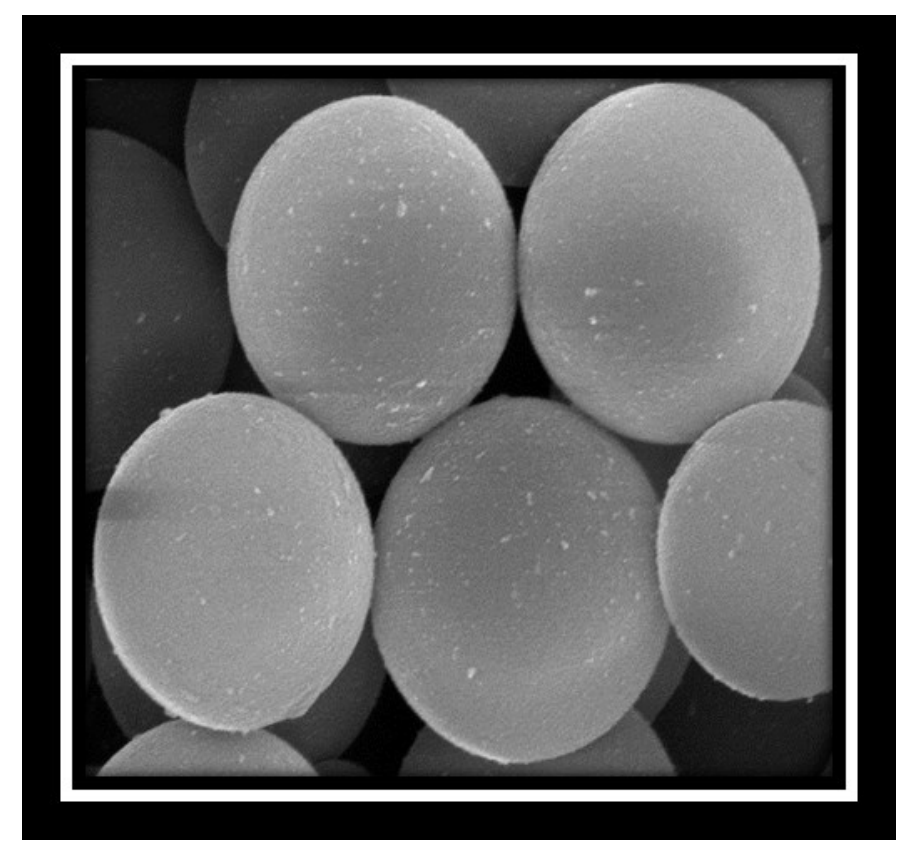

Fig 3 SEM image of PS particles. 


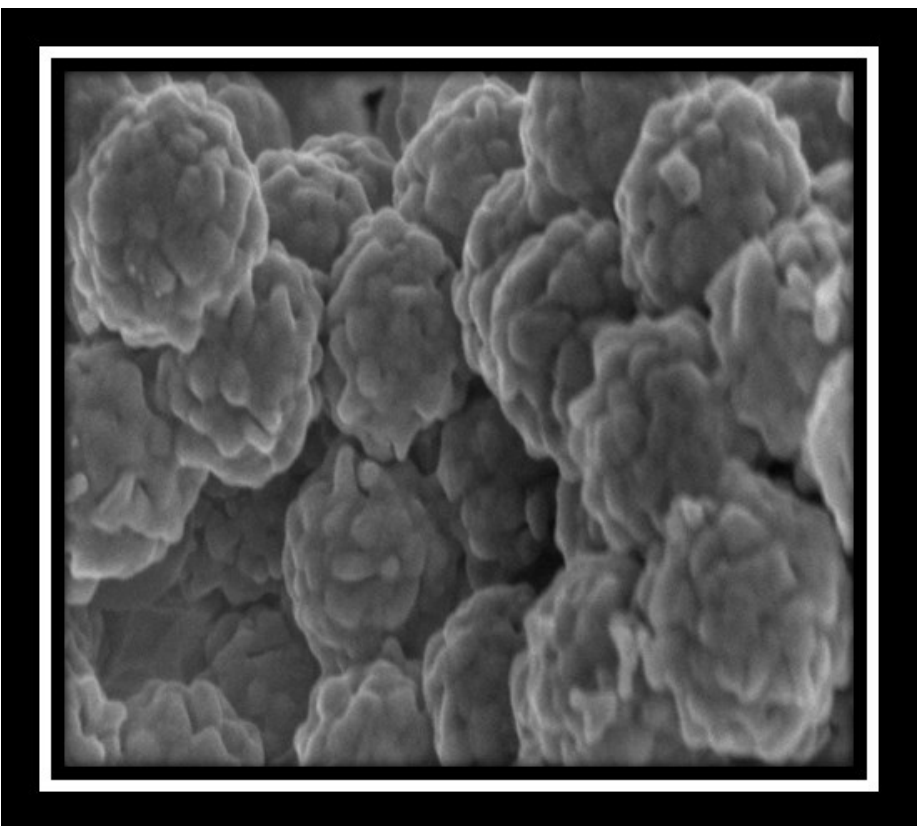

Fig 4 SEM image of PS@Au nanoshell.
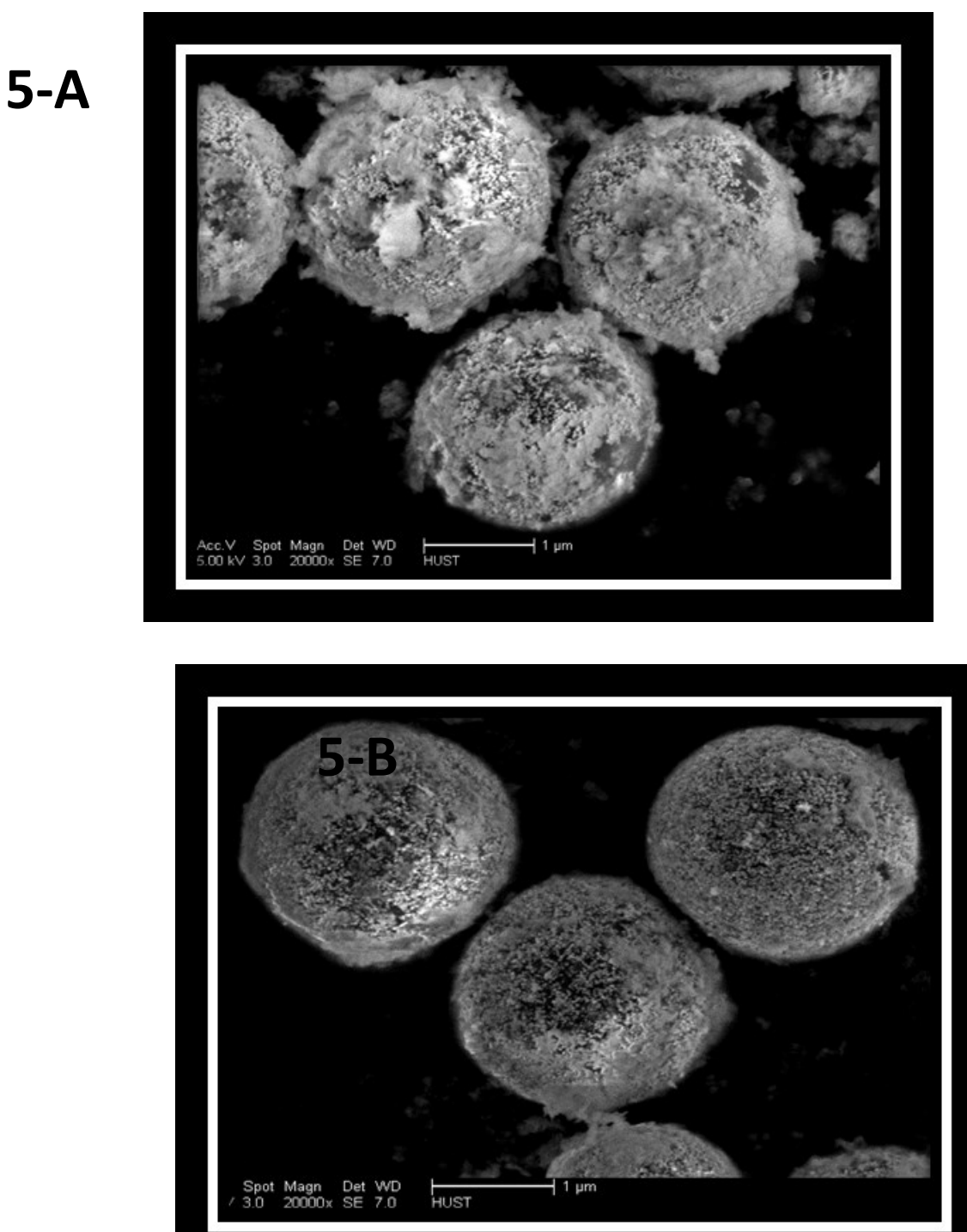


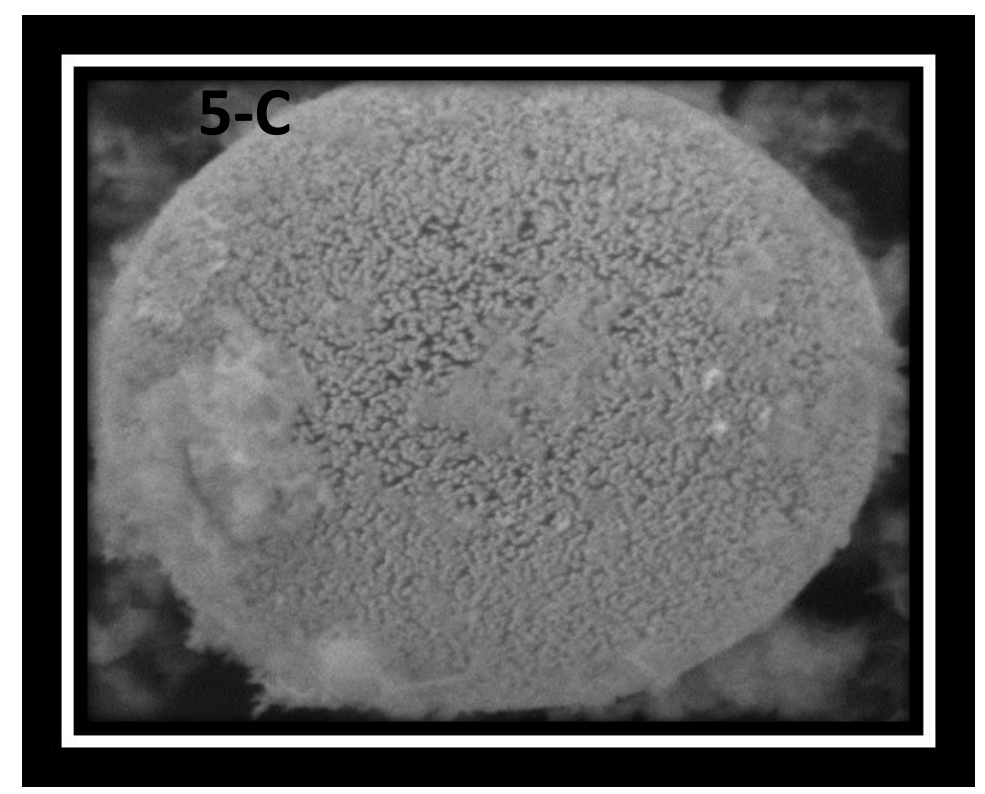

Figs 5. (A, B ,C) SEM composite PS@Au- $\mathrm{Cu}$ for different amount $\mathrm{CuSO}_{4} .5 \mathrm{H}_{2} \mathrm{O}$ molar solution are (a) 6ml; (b) $7 \mathrm{ml}$; (c) $8 \mathrm{ml}$; respectively.

5-D

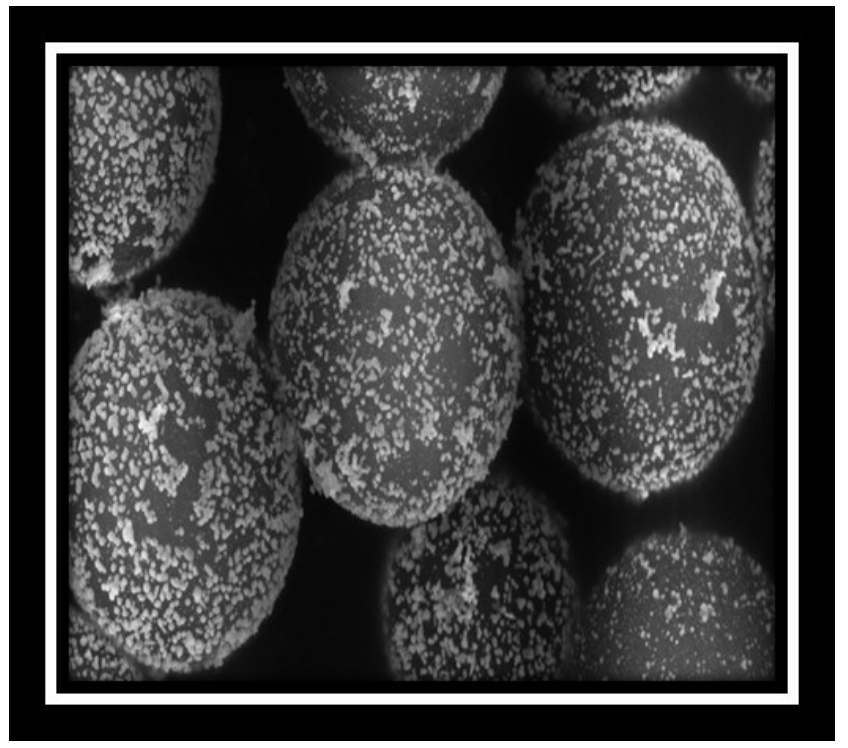

5-E

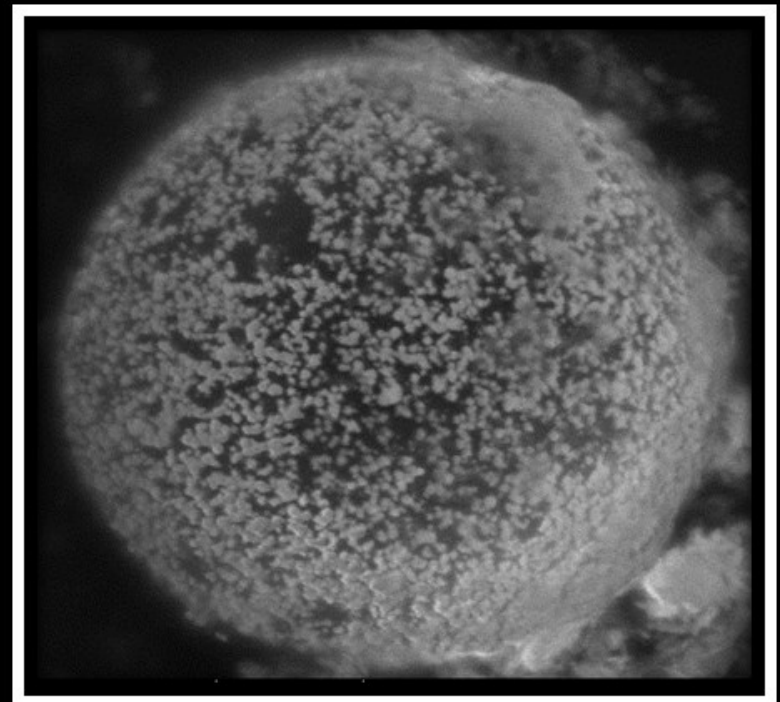



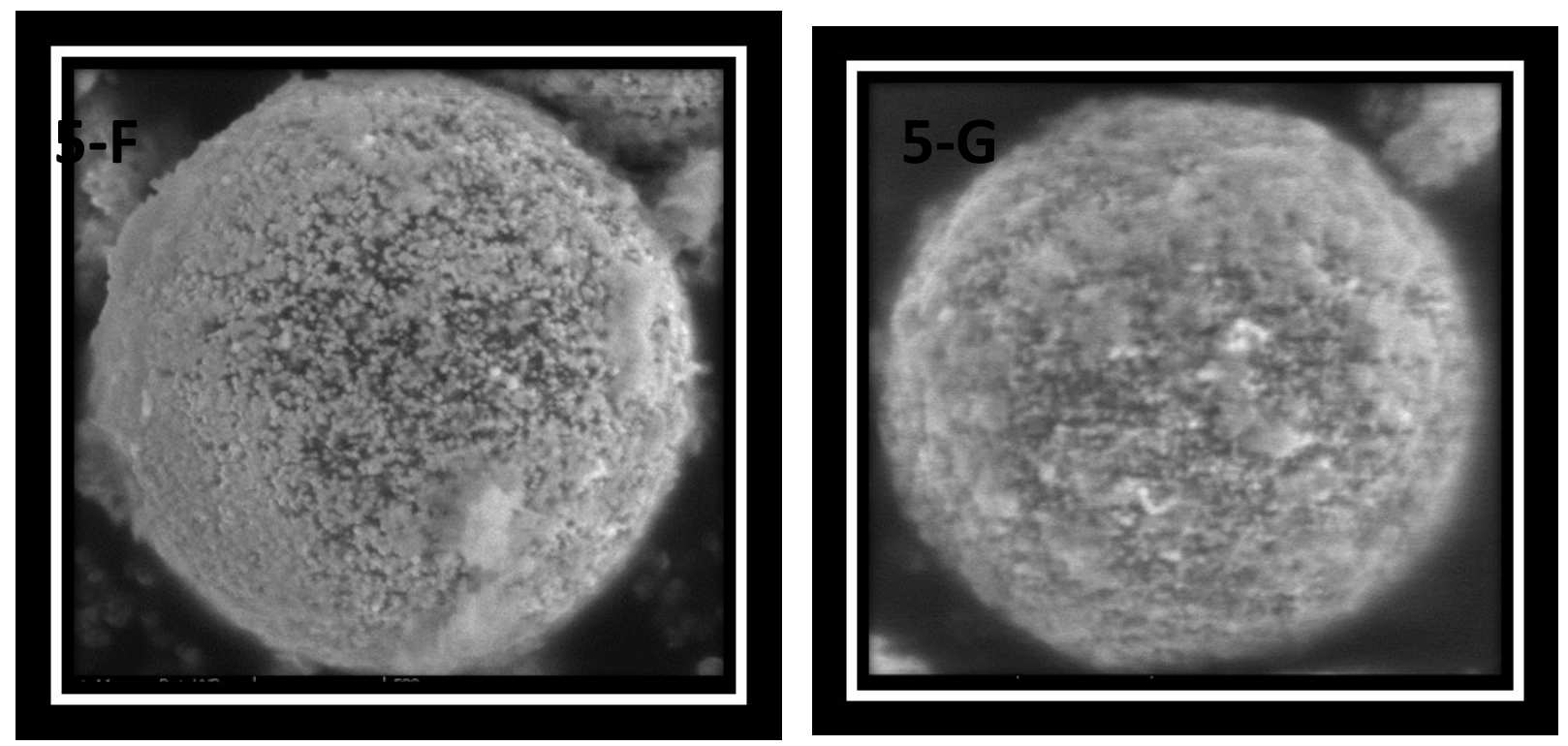

Figs 5. (D, E ,F, G) SEM composite PS@Au- Cu for different amount of $\mathrm{H}_{2} \mathrm{O}_{2}$ solution are (d)0. 6ml; (e) $0.8 \mathrm{ml} ;$ (f) $1 \mathrm{ml} ;(\mathrm{g}) 1.2 \mathrm{ml}$ respectively.

The surface morphologies of the samples before and after being coated with $\mathrm{Au}, \mathrm{Cu}$ NPs are studied by SEM, which are shown in Figures 3, 4, 5. Figure 3 present the typical SEM images of the bare PS microspheres It can be seen clearly that the formed PS microspheres are uniform, with smooth surfaces and a diameter about $300 \mathrm{~nm}$. Figure 3 demonstrate the typical SEM images of PS@Au- Nano shell thick shell fabricated using 1.5 M [K-H] solution . For figs 5 (A, B, C ) a sequence of SEM images PS@Au-Cu nanoparticles fabricated using different concentrations of $\mathrm{CuSO}_{4} .5 \mathrm{H}_{2} \mathrm{O}$ molar solution are (a) $6 \mathrm{ml}$; (b) $7 \mathrm{ml}$; (c) $8 \mathrm{ml}$; respectively. After being coated, the surfaces of the PS beads become rough. The shape of Au-Cu NPs is near-spherical and not have continuous single-crystalline shell structures, when add more molar solution all the NPs evenly coat the PS beads progressive to reach $98 \%$ the number of $\mathrm{Cu}$, Au particles greatly increases. About figs 4 (D, E, F, G ) SEM images of nanoshell grown with various volumes of $\mathrm{H}_{2} \mathrm{O}_{2}$ (a) $0.6 \mathrm{ml}$; (b) $0.8 \mathrm{ml}$; (c) $1 \mathrm{ml}$; (e) $1.2 \mathrm{ml}$ respectively. Quantity variation of increment made transfer in the shape of particles at first a little particles from $\mathrm{Au}-\mathrm{Cu}$ on the PS surface then more and more with increment amount, about $1.2 \mathrm{ml}$ was the best value to get approximation full shell in fig $4 \mathrm{~g}$.Also we can see small white clouds around the particles. This big clouds are from $\mathrm{NaOH}$. The alteration in amount of material not made shift in shape only, but also do transformation in the optical properties for this shapes cane see that from above for UV test wherein the best figs to get SPR ( surface plasmon resonance ) was $4 \mathrm{C}, 4 \mathrm{G}$.

\section{CONCLUSION}

This research has presented an experimental study of the effect of two materials amount of metal ion solutions, on the quality (i.e. morphology, shell completeness and optical properties) of PS@Au and PS@Au-Cu (core@shell) nanostructures prepared by the seed-and-grow method. Nano size PS spheres were prepared in the laboratory. Gold seeds were then linked to the functionalized PS spheres and the PS@metal nanoshell structures were formed by the subsequent reduction of metal onto the Au-seeded PS spheres from metal ion solutions. Results show that amount of $\mathrm{CuSO}_{4} .5 \mathrm{H}_{2} \mathrm{O}$ molar solution and $\mathrm{H}_{2} \mathrm{O}_{2}$ are important in controlled preparation of the nanoshells of good quality. A better seed coverage and good quality nanoshells are produced with big quantity .Also the nanostructure have continues absorption from blue shift increase and change to 
red shift These findings are confirmed by the SEM images of PS@Au-Cu coverage and metal shell morphology and by the UV-vis spectra of light absorption

\section{Reference}

[1] H.-P. Liang, H.-M. Zhang, J.-S. Hu, Y.-G. Guo, L.-J. Wan, C.-L. Bai, Pt Hollow Nano spheres: Facile Synthesis and Enhanced Electro catalysts, Angewandte Chemie International Edition, 43 (2004) 1540-1543.

[2] C. Loo, A. Lowery, N. Halas, J. West, R. Drezek, Immunotargeted Nano shells for Integrated Cancer Imaging and Therapy, Nano Letters,5 (2005) 709-711.

[3] J. Chen, F. Saeki, B.J. Wiley, H. Cang, M.J. Cobb, Z.-Y. Li, L. Au, H. Zhang, M.B. Kimmey, Li, Y. Xia, Gold Nano cages: Bio conjugation and Their Potential Use as Optical Imaging Contrast Agents, Nano Letters, 5 (2005) 473-477.

[4] J.L. Ou, C.P. Chang, Y. Sung, K.L. Ou, C.C. Tseng, H.W. Ling, M.D.Ger, Uniform polystyrene microspheres decorated with noble metal nanoparticles formed without using extra reducing agent, Colloids and Surfaces A: Physicochemical and Engineering Aspects, 305 (2007) 36-41.

[5] C. Jiang, S. Markutsys, V.V. Tsukruk, Langmuir 20 (2004) 882.

[6] J. Zhang, J. Liu, S. Wang, P. Zhan, Z. Wang, N. Ming, Adv. Funct.Mater. 14 (2004) 1089.

[7] S.J. Oldenburg, R.D. Averitt, S.L. Westcott, N.J. Halas, Chem. Phys.Lett. 288 (1998) 243.

[8] E. Prodan, C. Radloff, N.J. Halas, P. Nordlander, Science 302 (2003) 419.

[9] T. Ji, V.G. Lirtsman, Y. Avny, D. Davidov, Preparation, Characterization, and Application of Au-Shell/Polystyrene Beads and Au-Shell/Magnetic Beads, Advanced Materials, 13 (2001) 12531256.

[10] A.G. Dong, Y.J. Wang, Y. Tang, N. Ren, W.L. Yang, Z. Gao, Fabrication of compact silver nanoshells on polystyrene spheres through electrostatic attraction, Chemical Communications, (2002) 350-351.

[11] K.-T. Yong, Y. Sahoo, M.T. Swihart, P.N. Prasad, Synthesis and plasmonic properties of silver and gold nanoshells on polystyrene cores of different size and of gold-silver core-shell nanostructures, Colloids and Surfaces A: Physicochemical and Engineering Aspects, 290 (2006) 89105.

[12] Leyre Gomez,a Manuel Arruebo, *ab Victor Sebastian,ab Laura Gutierrezc and Jesus Santamaria*ab (2012). Facile synthesis of $\mathrm{SiO} 2-\mathrm{Au}$ nanoshells in a three-stage microfluidic system[J]. Journal of Dynamic ArticleLinks Materials Chemistry.

[13] Oldenburg, S.J.; Averitt, R.D.; Westeott, S.L.; Halas, N.J. Nanoengineering of optical resonances. Chem. Phys. Lett. 1998, 288, 243-247.

[14] Liang, Z.J.; Susha, A.S.; Caruso, F. Gold nanoparticle-based core-shell and hollow spheres and ordered assemblies thereof. Chem. Mater. 2003, 15, 3176-3183.

[15] Sridhar, B. et al (2008). Synthesis and Characterization of Silica@Copper Core-Shell Nanoparticles: Application for Conjugate Addition Reactions. Wiley-VCH Verlag GmbH\&Co. KGaA, Weinheim, 3, $1163-1169$.

[16] Gomez, Leyre. et al (2012). Facile synthesis of $\mathrm{SiO} 2-\mathrm{Au}$ nanoshells in a three-stage microfluidic system. Journal ofMaterials Chemistry, 21420-21425. 